Eur. J. Clin. Chem. Clin. Biochem.

Vol. 31, 1993, pp. $467-471$

(C) 1993 Walter de Gruyter \& Co.

Berlin - New York

\title{
Analytical and Clinical Utility of a Photometric Assay for Blood Coagulation Factor XIII
}

\author{
By J.W.J. van Wersch \\ Haematological Laboratory, De Wever Hospital, Heerlen, The Netherlands
}

(Received November 27, 1992/April 15, 1993)

Summary: A new photometric assay for factor XIII was evaluated for its analytical performance and clinical usefulness. The test showed good performance characteristics: intra-assay coefficients of variation between 0.83 and $2.68 \%$, inter-assay coefficients of variation from 3.4 to $4.5 \%$. The test can be conducted rapidly on an automated analyser such as the Cobas $\mathrm{Bio}^{\circledR}$. The reference values (mean $\pm 2 \mathrm{SD}$ ) ranged from 67 to $147 \%$ and there was no gender difference. The comparability of the photometric test with a clot lysis factor XIII test showed an acceptable coefficient of correlation $r=0.87(\mathrm{p}<0.0001)$. The diagnostic conformity of both tests was $76.7 \%$. Factor XIII concentrations were assessed in seven patient groups. In liver cirrhosis, $M$. Crohn and during pregnancy noticeable percentages of lowered values were found: i.e. $18.2 \%, 11.8 \%$ and $10.0 \%$ respectively. Elevated values were seen in hypertensive patients $(16 \%)$ and in the small group of patients with carcinoma of the ovarium $(22.2 \%)$. These results show that the incidence of acquired factor XIII deficiencies is relative low. The clinical meaning of reduced or enhanced factor XIII needs to be clarified by more extensive patient studies.

\section{Introduction}

Coagulation factor XIII is a zymogen (proenzyme), present in the circulation, which is transformed into its active form (factor XIIIa) by the proteolytic attack of thrombin in the presence of $\mathrm{Ca}^{2+}$. It is a transglutaminase (EC 2.3.2.13) catalysing an acyl transfer reaction. When a peptide-bound lysine residue is the acyl receptor, it cross-links two peptide chains (1).

The best known function of factor XIII is the crosslinking of fibrin to produce insoluble fibrin polymers (2). It simultaneously incorporates $\alpha_{2}$-antiplasmin into fibrin, thereby reducing the initial fibrinolytic activity (3). Moreover, factor XIII promotes the cross-linking of a fibronectin with fibrin (3). The interaction of factor XIII with collagen results in an acceleration of wound healing (4) and stimulates fibroblast proliferation $(5,6)$. In addition to its presence in plasma, factor XIII also occurs in platelets and placenta. Thrombocytic and placental factor XIII might be identical (7). Plasmatic factor XIII consists of two " $A$ " subunits complemented with a $S$ unit, whereas thrombocytic and placental factor XIII consist of two subunits "A" (8). Many attempts have been made to determine factor XIII and to introduce such determinations into laboratory diagnosis. For this purpose, several assays for factor XIII have been developed $(9-20)$. Most of them, however, are troublesome,

$$
\begin{aligned}
& \text { Factor XIII Thrombin, } \mathrm{Ca}^{2++} \\
& \text { Factor XIIIa } \\
& \text { Specific peptide }+ \text { Glycine-ethylester } \\
& \text { Peptide-Glycine-ethylester }+\mathrm{NH}_{3} \\
& \mathrm{NH}_{3}+\alpha-\text {-ketoglutarate }+\mathrm{NADH}+\mathrm{H}^{+} \\
& \text {Glutamate dehydrogenase } \\
& \text { Glumate }+\mathrm{NAD}^{+}
\end{aligned}
$$

Fig. 1. Principle of the photometric factor XIII assay (The specific peptide is composed of ten amino acids with the sequence Leu-Gly-Pro-Gly-Gln-Ser-Lys-Val-IleGly-amide). 
poorly reproducible, time consuming and not suitable for automation. Recently the Behring Corporation developed a new assay for factor XIII activity measurement. The principle of the assay (see fig. 1) is the release of ammonia when factor XIIIa catalyses the coupling of glycine-ethylester with a new specific dekapeptide with a $\mathrm{C}$-terminal amide group. The ammonia formed is determined from the decrease in absorbance at $340 \mathrm{~nm}$ due to dehydrogenation of $\mathrm{NADH}$ in the presence of glutamate dehydrogenase (EC 1.4.1.4) and 2-oxoglutarate. A peptide clot inhibitor is added to avoid interference due to gelation of the test mixture (21). In the present study we evaluated the analytical performance of the test, and applied it to a group of healthy volunteers and several patient groups.

\section{Materials and Methods}

Samples

Venous blood samples were collected from subjectively healthy individuals and from patients between 8.30 and $9.00 \mathrm{~h}$. Citrated plasma was prepared by centrifuging 9 volumes of freshly drawn blood with 1 volume of trisodium citrate $(0.11 \mathrm{~mol} / \mathrm{l})$ for 20 $\min$ at $1800 \mathrm{~g}$. The plasma was used immediately or stored at $-70^{\circ} \mathrm{C}$ in plastic tubes and thawed with tap water at $37^{\circ} \mathrm{C}$ for $5 \mathrm{~min}$ before use.

\section{Methods}

For the quantitative factor XIII assay we used the test kit of Behring (Marburg, Germany). For comparison purposes we performed the clot lysis assay according to Karges (1), also purchased from Behring (Marburg, Germany). The results of the clot lysis test are given as the highest dilution (range $25 \%$ to $200 \%$ in steps of $25 \%$ ) of plasma with a lysis resistant clot residue.

\section{Test procedure}

The determinations were performed on a Cobas $\mathrm{Bio}^{(1)}$ centrifugal analyser (Hoffmann La Roche, Basel, Switzerland). The measuring conditions for the Cobas Bio are given in table 1 .

\section{Patients}

The reference range was determined on 102 subjectively healthy volunteers (age range $20-50$ years, mean age 38 years. The test was also performed on patients with liver cirrhosis $(n=25)$, patients with M. Croln in the phase of exacerbation $(n=22)$, and on patients with hypertension $(n=51)$, with carcinoma of the lung $(n=48)$, of the colon $(n=23)$, of the ovarium $(n=9)$, and during pregnancy $(n=56)$. The same patients have been described in detail elsewhere $(22-26)$.

The patients with liver cirrhosis consisted of nine patients with Child-Turcotte classification A, nine patients with Child-Turcotte classification B and 7 patients with Child-Turcotte classification C. The patients with M. Crohn had a "van Hees" activity index ranging from $210-313$.

The hypertension patients consistently showed raised blood pressures: the diastolic pressure ranged between 90 and 144 $\mathrm{mmHg}$; the systolic pressure varied from $130-200 \mathrm{mmHg}$.
Tab. 1. Cobas Bio measuring conditions for the photometric factor XIII assay.

$\begin{array}{llc}1 \text { Units } & \text { Own } \\ 2 \text { Calculation factor } & ., & 0 \\ 3 \text { Standard 1 conc } & 99 \\ 4 \text { Standard } 2 \text { conc } & 99 \\ 5 \text { Standard 3 conc } & 99 \\ 6 \text { Limit } & 0 \\ 7 \text { Temperature }\left({ }^{\circ} \mathrm{C}\right) & 37.0 \\ 8 \text { Type of analysis } & 2 \\ 9 \text { Wavelength }(\mathrm{nm}) & 340 \\ 10 \text { Sample volume }(\mu \mathrm{l}) & 25 \\ 11 \text { Diluent volume }(\mu l) & 10 \\ 12 \text { Reagent volume }(\mu \mathrm{l}) & 250 \\ 13 \text { Incubation time }(\mathrm{s}) & 180 \\ 14 \text { Start reagent volume }(\mu \mathrm{l}) & 0 \\ 15 \text { Time of first reading }(\mathrm{s}) & 300.0 \\ 16 \text { Time interval }(\mathrm{s}) & 30 \\ 17 \text { Number of readings } & 10 \\ 18 \text { Blanking mode } & 1 \\ 19 \text { Printout mode } & 2\end{array}$

The carcinoma patients were untreated and recently diagnosed. The gestation periods of the pregnant women varied from $6-40$ weeks (mean 25.1 weeks).

\section{Results}

Reproducibility was tested at different factor XIII concentrations with samples obtained by mixing pooled normal plasma and factor XIII-deficient plasma or saline. The intra-assay coefficient of variation ranged from 0.83 to $2.68 \%$ depending on the tested concentration. The inter-assay coefficient of variation was $3.4 \%$ (at $95.8 \%$ factor XIII) and $4.5 \%$ at $55.1 \%$ factor XIII (see tab. 2).

Tab. 2. Reproducibility of the factor XIII assay (n.d. = not done).

\begin{tabular}{|c|c|c|c|c|c|}
\hline \multirow{2}{*}{$\begin{array}{l}\text { F XIII } \\
\text { concentration } \\
(\%)\end{array}$} & \multicolumn{2}{|c|}{ Intra-assay } & \multirow{2}{*}{$\begin{array}{l}\text { F XIII } \\
\text { concentration } \\
(\%)\end{array}$} & \multicolumn{2}{|c|}{ Inter-assay } \\
\hline & $\begin{array}{l}\text { CV } \\
(\%)\end{array}$ & $\mathrm{n}$ & & $\begin{array}{l}\text { CV } \\
(\%)\end{array}$ & $\mathrm{n}$ \\
\hline 120.0 & 0.83 & 20 & n.d. & n.d. & - \\
\hline 91.7 & 1.35 & 20 & 95.8 & 3.4 & 10 \\
\hline 53.3 & 2.68 & 20 & 55.1 & 4.5 & 10 \\
\hline 39.1 & 1.08 & 20 & n.d. & n.d. & - \\
\hline
\end{tabular}

Table 3 contains a contingency table of the photometric factor XIII results in comparison with those of the clot lysis factor XIII assay. Diagnostic confirmity was $76.7 \%$. A Spearman rank coefficient of correlation was calculated of $\mathrm{r}=0.87$; $\mathrm{p}<0.0001$.

The reference values (tab. 4) were calculated from 102 subjectively healthy individuals ( 46 males, 56 females). No differences were seen between the sexes. The average value was $107 \%$, the median value $104 \%$. Since 
Tab. 3. Diagnostic conformity $(76.7 \%)$ of the photometric and the clot lysis factor XIII tests $(n=155)$.

Number of samples at each factor XIII concentration determined by clot lysis

\begin{tabular}{lrrrr} 
& & $0-75 \%$ & $75-125 \%$ & $125-200 \%$ \\
\hline Number of samples & $0-75 \%$ & 8 & 20 & 0 \\
at each factor XIII concentration & $75-150 \%$ & 0 & 107 & 16 \\
determined by the photometric assay & $>150 \%$ & 0 & 0 & 4 \\
\hline
\end{tabular}

Tab. 4. Basic statistics and reference range of a group of healthy volunteers.

\begin{tabular}{lc}
\hline & $\begin{array}{l}\text { Factor XIII } \\
\text { plasma } \\
\text { concentration }\end{array}$ \\
\hline Average & $107 \%$ \\
Median & $104 \%$ \\
Standard deviation (SD) & $20 \%$ \\
Lower quartile & $91 \%$ \\
Upper quartile & $123 \%$ \\
Interquartile range & $31 \%$ \\
\hline Reference range & $67-147 \%$ \\
(mean \pm 2 SD) & \\
\hline
\end{tabular}

the distribution was Gaussian, the reference values were taken as mean value \pm 2 SD i.e. $67-147 \%$.

In table 5 the results of the factor XIII concentrations in different disease states are given. High percentages of low values were found in liver cirrhosis $(18.2 \%)$, M. Crohn (11.8\%), carcinoma of the ovarium (22.2\%) and during pregnancy $(10.0 \%)$. High proportions of elevated values were seen in hypertensive patients $(16 \%)$ and in carcinoma of the ovarium $(22.2 \%)$.

\section{Discussion}

The newly available kinetic factor XIII assay showed good reproducibility, comparable to that reported in the literature (27). Comparability with a clot stability test was also satisfactory and in close agreement with other results (27). The reference values were also in concordance with those reported in the literature (27). The new test shows good performance characteristics; it is also rapid, easy to perform and shows good reproducibility. With regard to the clinical usefulness of the test, we know from the literature that a congenital factor XIII deficiency is the exception, whereas the acquired form is relatively common. As early as 1972 , a substantial decrease was reported in patients with acute leukaemia (28). Another case of factor XIII deficiency was reported in 1982 by Kuratsuji et al. (29) in antibiotic-associated pseudo-membranous colitis. A successful pregnancy of a woman with congenital factor XIII deficiency treated with substitutive therapy has been described by Rodeghiero et al. (30) and Boda et al. (31). Several studies have dealt with low factor XIII concentrations in Crohn's disease (32) and colitis ulcerosa (33) and the treatment of patients suffering from these diseases with factor XIII concentrate $(34,35)$. Most recently, factor XIII deficiencies were reported in systemic haematological disorders, morbus Schönlein Hennoch and bacterial infections, as well as in inflammatory bowel disease (36). Regarding the clinical usefulness of the test, we conclude from the results of the present study that the photometric factor XIII test is useful for the detection of moderate deficiencies as established in patients with

Tab. 5. Values for factor XIII in several patient groups.

\begin{tabular}{|c|c|c|c|c|c|c|c|}
\hline \multirow[t]{2}{*}{ Patient groups } & & \multicolumn{6}{|c|}{ F XIII concentrations $(\%)$} \\
\hline & & $\overline{\mathbf{x}}$ & $\mathrm{SD}$ & Min & $\operatorname{Max}$ & $\begin{array}{l}\text { FXIII } \\
\text { decreased') }\end{array}$ & $\begin{array}{l}\text { FXIII } \\
\text { increased }^{2} \text { ) }\end{array}$ \\
\hline $\begin{array}{l}\text { Liver cirrbosis } \\
\text { M. Crohn in acute phase }\end{array}$ & $(n=25)$ & 97.0 & 29.6 & 36 & 166 & 18.2 & 3.0 \\
\hline with thrombocytosis & $(\mathrm{n}=22)$ & 100.0 & 22.1 & 47 & 136 & 11.8 & 0 \\
\hline Hypertension & $(n=51)$ & 110.6 & 24.6 & 72 & 173 & 9 & 16.0 \\
\hline Carcinoma of the lung & $(n=48)$ & 104.4 & 26.4 & 58 & 163 & 4.7 & 7.0 \\
\hline Carcinoma of the colon & $(n=23)$ & 102.7 & 17.8 & 65 & 146 & 4.3 & 4.3 \\
\hline Carcinoma of the ovarium & $(\mathrm{n}=9)$ & 110.1 & 39.9 & 56 & 183 & 22.2 & 22.2 \\
\hline Pregnancy & $(n=56)$ & 93.7 & 19.6 & 54 & 136 & 10.0 & 0 \\
\hline
\end{tabular}

') percentage of values beneath the lower limit of the reference range.

$\left.{ }^{2}\right)$ percentage of values above the upper limit of the reference range. 
liver cirrhosis, morbus Crohn and during pregnancy. It must be considered that the evaluation of protein changes during pregnancy is complicated by the redistribution of body water with increasing gestational age, which might cause a lowering of protein concentrations. In the present study, however, factor XIII did not show a significant decrease with ongoing pregnancy $(r=-0.026, n$. s.). Nevertheless, lowered factor XIII during pregnancy may be partly due to the described effect.

\section{References}

1. Karges, H. E. \& Clemens, R. (1988) Factor XIII: enzymatic and clinical aspects. Behring Inst. Mitt. 82, 43-58.

2. Laki, K. \& Lorand, L. (1948) On the solubility of fibrin clots. Science 108: 280

3. Sakata, Y. \& Aoki, N. (1928) Significance of cross-linking of $\alpha_{2}$-plasmin inhibitor to fibrin in inhibition of fibrinolysis and in haemostasis. J. Clin. Invest. 68, 536-542.

4. Baer, I., Bauknecht, J., Stangl, T. \& Häring, R. (1980) Verminderung von Wundheilungsstörungen durch prä- und postoperative quantitative Faktor-XIII Substitution. Zentralbl. Chir. 105, 642-651.

5. Beck, E. A., Duckert, F. \& Ernst, M. (1961) The influence of fibrin stabilizing factor on the growth of fibroblasts in vitro and wound healing. Thromb. Diath. Haemorrh. 6 , 485-491.

6. Paye, M., Nusgens, B. V. \& Lapiëre, C. M. (1989) Factor XIII of blood coagulation modulates collagen biosynthesis by fibroblasts in vitro. Haemostasis 19, 274-283.

7. Bohn, H. (1971) Immunochemical studies on the fibrin stabilizing factors from human plasma and platelets. Blut $22,237-243$.

8. Bohn, H., Becker, W. \& Trobisch, H. (1973) Die molekulare Struktur der fibrinstabilisierenden Faktoren des Menschen. Blut 26, 303-311.

9. Francis, J. L. (1988) Detection and measurement of factor XIII. In: Fibrinogen, Fibrin Stabilisation and Fibrinolysis (Francis, J. L., ed.) Chichester England: Ellis Horwood Ltd., pp. 203-222.

10. Lee, K. N., Birckbichler, P. J. \& Patterson, J. K. Jr. (1988) Colorimetric assay of blood coagulation factor XIII in plasma. Clin. Chem. 34, 906-910.

11. Velasco, P. T., Karush, F. \& Lorand, L. (1988) Transaminating activities of factor XIIIa and of transglutaminases. measured by an Elisa procedure. Biochem. Biophys. Res. Commun. 152, 505-511.

12. Mousil, S. \& Wakid, N. W. (1977) Ammonia production during clot retraction and its use in assay of fibrinoligase. Clin. Chem. 23, 1739-1743

13. Muszebek, L., Polgar, J. \& Fesüs, L. (1985) Kinetic determination of blood coagulation factor XIII in plasma. Clin. Chem. 31, 35-40.

14. Jacobsen, E. \& Godal, H. C. (1974) Simple semiquantitative test for partial factor XIII (FSF) deficiency. Scand. J. Haemat. 12, 366-368.

15. Karges, H. E. (1984) Blood coagulation F XIII: Determination by clot stability assays. In: Methods of Enzymatic Analysis (Bergmeyer, H. U., ed.) 3rd ed., Weinheim: Verlag Chemie, $400-410$.

16. Bohn, H. \& Haupt, H. (1968) Eine quantitative Bestimmung von Faktor XIII mit Anti-Faktor XIII Serum. Thromb. Diath. Haemorrh. 19, 309-315.

17. Egbring, R., Schmidt, W. \& Havemann, K. (1973) Die vereinfachte radiologische Faktor XIII-Bestimmung und ihre klinische Anwendung bei kongenitalem Faktor XIIIMangel. Blut 27, 6-19.
The detection of elevated factor XIII might also be of clinical value, e.g. in hypertensive patients and perhaps in patients with carcinoma of the ovarium, although this group is too small to draw definitive conclusions. The demonstrated incidence of decreased or increased values, however, seems to be relatively low. The clinical significance of the observed raised or lowered factor XIII values is therefore not clear. More extensive clinical studies are required to address these issues.

18. Nelson, J. C. \& Lerner, R. G. (1978) Detection of factor XIIla (active fibrin-stabilizing factor) in normal plasma. Blood 52, $581-591$.

19. Carlebjörk, G. (1981) A precise routine method for detection of F XIII activity in plasma. Thromb. Res. 21, 507511 .

20. Hellstern, P. Schilz, K. v. Blohn, G. \& Wenzel, E. (1983) Determination of factor XIII activity and of factor XIII inhibitors using an ammonium sensitive electrode. Thromb. Haemstas. 50, 563-566.

21. Laudano, E. P. \& Doolittle, R. F. (1980) Studies on synthetic peptides that bind to fibrinogen and prevent fibrin polymerisation. Structural requirements, number of binding sites and species differences. J. Biol. Chem. 19, 10131019.

22. van Wersch, J. W. J., Russell, M. G. V. M. \& Lusterman, F. A. Th. (1992) The extent of diffuse intravascular coagulation and fibrinolysis in patients with liver cirrhosis. Eur. J. Clin. Chem. Clin. Biochem. 30, 275-279.

23. van Wersch, J. W. J., Houben, P. \& Rijken, J. (1990) Platelet count, platelet function, coagulation activity and fibrinolysis in the acute phase of inflammatory bowel disease. J. Clin. Chem. Clin. Biochem. 28, 513-517.

24. van Wersch, J. W. J., Rompelberg-Lahaye, J. \& Lustermans, F. A. Th. (1991) Plasma concentration of coagulation and fibrinolysis factors and the level of platelet function in hypertension. Eur. J. Clin. Chem. Clin. Biochem. 29, 375379.

25. van Wersch, J. W. J. \& Tjwa, M. K. T. (1991) The coagulation/fibrinolysis balance and lung cancer. Haemostasis $21,117-123$.

26. van Wersch, J. W. J. \& Ubachs, J. M. H. (1991) Blood coagulation and fibrinolysis during normal pregnancy. Eur. J. Clin. Chem. Clin. Biochem. 29, 45-50.

27. Fickenscher, K., Aab, A. \& Stüber, W. (1991) A photometric assay for blood coagulation factor XIII. Thromb. Haemostas. 61, 535-540.

28. Rasche, H., Dietrich, M. \& Hiemeyer, V. (1972) Untersuchungen über die Faktor XIII-Aktivität im Plasma bei akuter Leukaemie. Klin. Wochenschr. 50, 1017-1019.

29. Kuratsuji, T., Oikawa, T., Fukumoto, T., Shimizu S., Iwasaki, Y. Tomita, Y., Meguro, T. \& Yamada, K. (1982) Factor XIII deficiency in antibiotic-associated pseudomembranous colitis and its treatment with factor XIII concentrate. Haemostasis $11,229-234$.

30. Rodeghiero, F., Castaman, G. C., Di Bona, E., Ruggeri, M. \& Dini, E. (1987) Successful pregnancy in a woman with congenital factor XIII deficiency treated with substitutive therapy. Report of a second case. Blut 55, 45-48.

31. Boda, Z., Pfliegler, G., Muszbek, L., Toth, A., Adany, R., Rarsfalvi, J., Papp, Z., Tornai, I. \& Rak, K. (1989) Congenital factor XIII deficiency with multiple benign breast tumours and successful pregnancy with substitutive therapy. A case report. Haemostasis $19,348-352$. 
32. Wisen, O. \& Gårlund, B. (1988) Hemostasis in Crohn's disease: low factor XIII levels in active disease. Scand. J. Gastroenterol. 23, 961-966.

33. Suzuki, R., Toda, H. \& Takamura, Y: (1989) Dynamics of blood coagulation factor XIII in ulcerative colitis and preliminary study of the factor XIII concentrate. Blut 59, $162-164$

34. Lorenz, R., Clemelns, R., Karl, M. \& Classen, M. (1989) Substitution von F XIII-Konzentrat bei Colitis ulcerosa. Z. Gastroenterol. 27, 87-90.
35. Lorenz, R. \& Heinmüller, M. (1990) Substitution of factor XIII concentrate in ulcerative colitis. Blut 60, 138 (abstract). 36. Egbring, R., Keiling, A., Kehl, H. G., Seitz, R., Wallin, R. \& Saldeen, T. (1990) Factor XIII deficiency in inflammatory bowel disease, systemic haematological disorders, Morbus Schönlein Hennoch (MSH) and bacterial infections. Treatment of bleeding complications by factor XIII concentrates. Blut 60,121 (abstract).

Dr. J. W. J. van Wersch

Haematological Laboratory

De Wever Hospital

P. O. Box 4446

NL-6401 CX Heerlen 
